\title{
Loss of Presynaptic and Postsynaptic Structures Is Accompanied by Compensatory Increase in Action Potential-Dependent Synaptic Input to Layer V Neocortical Pyramidal Neurons in Aged Rats
}

\author{
Tak Pan Wong, ${ }^{1}$ Giorgio Marchese, ${ }^{1}$ Maria Antonietta Casu, ${ }^{1}$ Alfredo Ribeiro-da-Silva, ${ }^{1,2}$ A. Claudio Cuello, ${ }^{1,2}$ \\ and Yves De Koninck \\ ${ }^{1}$ Departments of Pharmacology and Therapeutics, and ${ }^{2}$ Anatomy and Cell Biology, McGill University, Montreal, Quebec, \\ Canada, H3G 1 Y6
}

\begin{abstract}
Reduction in both presynaptic and postsynaptic structures in the aging neocortex may significantly affect functional synaptic properties in this area. To directly address this issue, we combined whole-cell patch-clamp recording of spontaneously occurring postsynaptic currents (PSCs) with morphological analysis of layer $\mathrm{V}$ pyramidal neurons in the parietal cortex of young adult (1to 2-month-old) and aged (28- to 37-month-old) BNxF344 $F_{1}$ hybrid rats. Analysis of spontaneous PSCs was used to contrast functional properties of basal synaptic input with structural alterations in the dendritic tree of pyramidal neurons and density of terminals in contact with these cells.

We observed significant changes in a number of morphological parameters of pyramidal neurons in aged rats. These include smaller cell body size and fewer basal dendritic branches (but not of oblique dendrites and dendritic tufts) and spines. Ultrastructural analysis also revealed a lower density of presynaptic
\end{abstract}

Layer V pyramidal neurons in the cerebral cortex, the principal output cells from this area (Feldman, 1984; Landry et al., 1984; De Felipe and Farinas, 1992), have been shown to exhibit significant structural modifications in aging. Decreases in the number of dendritic structures of layer $\mathrm{V}$ pyramidal neurons have been reported in the aging neocortex (Feldman and Dowd, 1975; Leuba, 1983; Nakamura et al., 1985; Lolova et al., 1990; Jacobs et al., 1997). These atrophies may result in a loss of synaptic substrate. Furthermore, age-related decreases in the number of cortical synapses have also been reported (Huttenlocher, 1979; Adams, 1987; Markus and Petit, 1987; Zecevic et al., 1989; Bourgeois and Rakic, 1993). Interestingly, there is also evidence that supports a more profound reduction of both dendrites and synapses in deep cortical layers of aged rats (V, VI) than in superficial layers (Wong et al., 1998; de Brabander et al., 1998). Preferential reductions of presynaptic and postsynaptic structures in these cortical layers may reflect specific loss of functional synaptic inputs to layer $\mathrm{V}$ pyramidal neurons.

\footnotetext{
Received June 22, 2000; revised Aug. 30, 2000; accepted Aug. 30, 2000.

This work was supported by Canadian Medical Research Council (MRC) Grants MT 14494 to A.C.C and MT 12942 to Y.D.K. and by National Institute for Neurological Disorders and Stroke Grant NS-34022 to Y.D.K. We acknowledge a grant on "Structural/Functional Modeling and Imaging" from SmithKline Beecham (Canada) and would like to thank Drs. P. Somogyi and P. Bolam for valuable advice on the histological preservation of brain slices. Y.D.K. is a Scholar of the Canadian MRC. T.P.W. was the recipient of scholarships from the Alzheimer Society of Canada, the Croucher Foundation, and the Fonds pour la Formation de Chercheurs et l'Aide à la Recherche du Québec.

Correspondence should be addressed to Dr. A. Claudio Cuello, Department of Pharmacology and Therapeutics, McGill University, 3655 Promenade Sir-WilliamOsler, Montreal, Quebec H3G 1Y6, Canada. E-mail: accuello@Pharma.McGill.CA.

Drs. Marchese and Casu's present address: Dipartimento di Neuroscienze, Via Porcell 4, 09124 Cagliari, Italy.

Copyright (C) 2000 Society for Neuroscience $0270-6474 / 00 / 208596-11 \$ 15.00 / 0$
}

terminals per unit length of postsynaptic membrane of labeled pyramidal neurons in the aged brain. This reduction in both presynaptic and postsynaptic elements was paralleled by a significant decrease in frequency of tetrodotoxin-insensitive miniature (action potential-independent) PSCs (mPSCs). The frequency of excitatory and inhibitory mPSCs was reduced to the same extent. In contrast, no significant change was observed in the frequency of spontaneous PSCs recorded in absence of tetrodotoxin (sPSCs), indicating an increase in action potentialdependent (frequency sPSCs $_{\text {- }}$ - frequency $_{\text {mPscs }}$ ) input to pyramidal neurons in the aged group. This functional compensation may explain the lack of drastic loss of spontaneous neuronal activity in normal aging.

Key words: aging; dendritic morphometry; electron microscopy; EPSC; IPSC; parietal cortex; patch-clamp; spontaneous synaptic activity

Loss of synaptic elements in layer $\mathrm{V}$ neocortical pyramidal neurons may result in a decline of function in the aged brain. Studies of glucose utilization (Leenders et al., 1990) and blood flow (Melamed et al., 1980; Shaw et al., 1984; Gur et al., 1987) revealed significant reduction in metabolic activity in the aged cerebral cortex. In addition, a profound reduction of dendritic spines in the aged brain may suggest a major loss of asymmetric synapses (White, 1989). Given that these asymmetric synapses have been suggested to be excitatory (Uchizono, 1965; Gray, 1969; De Felipe and Farinas, 1992), age-related synaptic loss may result in a preferential reduction of excitatory rather than inhibitory synaptic inputs to cortical pyramidal neurons. Although decreases in cortical neuronal activities have been reported (Stern et al., 1985; Roy and Singh, 1988), no major loss of spontaneous firing rate of layer V pyramidal neurons was shown (Lamour et al., 1985; Stern et al., 1985). Interestingly, similar stability of cellular characteristics in the aged brain has been observed in the hippocampus (for review, see Barnes, 1994). One of the possible explanations of this discrepancy is a compensatory functional change in synaptic transmission after loss of synapses.

To test this possibility, we performed whole-cell patch-clamp recordings of spontaneous synaptic events in layer $\mathrm{V}$ pyramidal neurons of the neocortex to study action potential-dependent spontaneous postsynaptic currents (sPSCs) and action potentialindependent miniature PSCs (mPSCs) in morphologically characterized layer $\mathrm{V}$ pyramidal neurons in the parietal cortex of young adult (1- to 2-month-old) and aged (29- to 37-month-old) Brown Norway $\times$ Fischer $344 \mathrm{~F}_{1}\left(\mathrm{BNxF} 344 \mathrm{~F}_{1}\right)$ hybrid rats. This strain has the advantage of enhanced resistance to tumors and other genetic diseases with respect to its parental inbred strains (Hazzard et al., 1992; Spangler et al., 1994), minimizing variability between aged individuals. Each recorded neuron was labeled with biocytin and reconstructed by camera lucida for complete morphometric analy- 
sis of its soma and dendritic structure for comparison with properties of spontaneous PSCs.

\section{MATERIALS AND METHODS}

Animals. Twenty-three young adult (1- to 2-month-old; $1.8 \pm 0.1$ months) and 25 aged (29- to 37-month-old; $31.9 \pm 0.4$ ) BNxF344 $F_{1}$ hybrid rats (National Institute on Aging) were used in this study. The reference young adult animals used in this study were considered as adult rats because synaptic inputs to pyramidal neurons in this age range have been shown to be both morphologically (Blue and Parnavelas, 1983) and physiologically (Luhmann and Prince, 1991; Sutor and Luhmann, 1995) mature. In contrast to several other studies using prenatal or early postnatal (1- to 21 -d-old) animals, the young adult ( $>30$-d-old) group used in the present study allowed us to evaluate alterations with aging that occur after full maturation of the cortex. Aged animals with obvious pathological symptoms and palpable tumors were discarded.

Slice preparation. Half of the young and aged animals were anesthetized intraperitoneally with $1 \mu \mathrm{l}$ of sodium pentobarbital (Somnotol; MTC Pharmaceuticals) per gram of animal weight before decapitation. Whereas no differences in all experimental findings were observed among the anesthetized and unanesthetized groups, data from these two groups were pooled together. All experiments were approved by the University Animal Care Committee and conducted in accordance with its guidelines. After decapitation, brains were removed and immersed in ice-cold oxygenated $\left(95 \% \mathrm{O}_{2}\right.$ and $5 \% \mathrm{CO}_{2}$ ) sucrose-substituted ACSF (S-ACSF) containing (in mM): 252 sucrose, $2.5 \mathrm{KCl}, 2 \mathrm{CaCl}_{2}, 2 \mathrm{MgCl}_{2}, 10$ glucose, $26 \mathrm{NaHCO}_{3}$, $1.25 \mathrm{NaH}_{2} \mathrm{PO}_{4}$ (Fisher Scientific, Houston, TX), 5 kynurenic acid, and pyruvic acid (Sigma, St. Louis, MO; pH 7.35; 340-350 mOsm) for 1 min. Using this Ringer's solution improves the survival of brain slices (Richerson and Messer, 1995). The brains were then glued caudal side down on a brass platform with cyanoacrylate cement in a chamber filled with oxygenated ice-cold S-ACSF, and 400- $\mu$ m-thick coronal sections were cut between bregma $0.5 \mathrm{~mm}$ and $-3.0 \mathrm{~mm}$ (which contains both the parietal I and II regions; Paxinos and Watson, 1986) with a Vibratome (TPI series 1000). Freshly cut slices were incubated in oxygenated S-ACSF at room temperature. After $30 \mathrm{~min}$ incubation, slices were transferred to a storage chamber filled with oxygenated normal ACSF $(126 \mathrm{~mm} \mathrm{NaCl}$ instead of sucrose; 300-310 mOsm). Slices were incubated in this chamber at room temperature for at least $1 \mathrm{hr}$ before performing any electrophysiological recording. An interface brain slice recording chamber with $\sim 1 \mathrm{ml} / \mathrm{min}$ perfusion of oxygenated ACSF containing $5 \mathrm{~mm} \mathrm{KCl}$ was used for patch-clamp recording. Recordings were performed at $33^{\circ} \mathrm{C}$.

Whole-cell patch-clamp recording. Patch pipettes were pulled from borosilicate glass capillaries (World Precision Instruments) and filled with an intracellular solution ( $\mathrm{pH} 7.2 ; 275-280 \mathrm{mOsm}$ ) composed of (in mM): 100 Cs gluconate, $5 \mathrm{CsCl}, 10 \mathrm{HEPES}, 2 \mathrm{MgCl}_{2}, 1 \mathrm{CaCl}_{2}, 11$ BAPTA, 4 ATP, 0.4 GTP, $0.5 \%$ Lucifer Yellow (Sigma), and $0.2 \%$ biocytin (Calbiochem, La Jolla, CA). The junction potential of the pipette was corrected by subtracting $10 \mathrm{mV}$ from the recorded membrane voltages (Staley and Mody, 1992). An Axopatch 200A amplifier (Axon Instruments, Foster City, CA) with $>75 \%$ series resistance compensation was used for the recording. The access resistance was monitored throughout each experiment (average $14.6 \pm 0.7 \mathrm{M} \Omega$ ), and only recordings with stable access were used. Whole-cell patch-clamp recordings were performed in voltage-clamp mode while maintaining the membrane potential either at the reversal potential for $\mathrm{GABA}_{\mathrm{A}}$ receptor-mediated PSCs $(-60 \mathrm{mV})$ to isolate EPSCs or at the reversal potential for ionotropic glutamate receptormediated PSCs $(0 \mathrm{mV})$ to isolate IPSCs. The recorded spontaneous EPSCs and IPSCs were antagonized completely by the ionotropic glutamate receptor antagonist cyano-7-nitroquinoxaline-2,3-dione (CNQX; Research Biochemicals, Natick, MA) and by the $\mathrm{GABA}_{\mathrm{A}}$ receptor antagonist bicuculline (Research Biochemicals), respectively. At the beginning of each recording, 200-msec-long, hyperpolarizing pulses were used to measure the input resistance and membrane time constant of each neuron. The membrane time constant was obtained by fitting the decay portion of the response with multiple exponential functions (Rall, 1969; Jackson, 1992; Spruston and Johnston, 1992). The slowest time constant was then used to calculate the membrane capacitance. The $\left[\mathrm{K}^{+}\right]$was raised to $5 \mathrm{~mm}$ in the bathing solution to increase the frequency of PSCs (Bao et al., 1998). In a number of experiments, tetrodotoxin (TTX; $1 \mu \mathrm{M}$ from RBI) was also added to the ACSF to block voltage-gated sodium channels and isolate action potential-independent mPSCs. Recordings were low-pass filtered at $10 \mathrm{kHz}$, stored on a videotape using a digital data recorder (VR-10B; Instrutech). Stored recordings were played back offline, low-pass filtered at $3 \mathrm{kHz}$, and sampled at $10 \mathrm{kHz}$ on an Intel Pentium-based computer using the Strathclyde Electrophysiology software (by J. Dempster, Department of Physiology and Pharmacology, University of Strathclyde, Glasgow, UK).

Signal analysis. Analysis of SPSCs was performed offline using locally designed software (De Koninck). Frequencies, peak amplitudes, rise times and decay time constants were calculated for each of several hundred sPSCs and mPSCs per cell, using an automated algorithm (De Koninck and Mody, 1994; Chéry and De Koninck, 1999). The goodness of fit was evaluated on the basis of fitting subsets of points drawn from the whole set of data points as well as from evaluation of the reduced $\chi^{2}, \chi^{2}=\chi^{2} / v$ where the factor $\nu=N-n$ is the number of degrees of freedom left after fitting $N$ data points to the $n$ parameters. The necessity to introduce additional exponential components to the fits was judged first on the basis of visual inspection of the fitted curves superimposed onto the data. When the merit of additional components was not obvious, an $F$ test was used to assess how the additional component improved the value of the reduced $\chi^{2}: F_{\mathrm{x}}=\Delta \chi^{2} / \chi^{2}\left(\mathrm{df}_{1}=1\right.$ and $\left.\mathrm{df}_{2}=\nu\right)$. The critical value for the merit of additional components was set at a low level $(p<0.01)$ to favor parsimony of the fitted function.

Morphometric analysis. After the recording, slices were immersed in fixative containing $4 \%$ paraformaldehyde (PF; BDH) and $0.5 \%$ glutaraldehyde (GA; Meca Lab) in $0.1 \mathrm{M}$ phosphate buffer (PB), $\mathrm{pH} 7.4$, for $2 \mathrm{hr}$ at room temperature and post-fixed overnight in $4 \% \mathrm{PF}$ at $4^{\circ} \mathrm{C}$. The tissue was then embedded with $10 \%$ gelatin (Sigma), post-fixed for $1 \mathrm{hr}$ with $4 \%$ $\mathrm{PF}, 0.1 \% \mathrm{GA}$, and $15 \%$ picric acid in $\mathrm{PB}$, and resectioned at $100-\mu \mathrm{m}$-thick sections with a Vibratome. Free-floating cytochemical staining was performed as previously described (Côté et al., 1993). PBS (0.01 M, pH 7.4) with $0.2 \%$ Triton $\mathrm{X}-100$ (PBS $+\mathrm{T}$; $\mathrm{BDH}$ ) was used for washing and diluting reagents throughout the experiments, and two PBS $+\mathrm{T}$ washes were performed between each incubation. Endogenous peroxidase activity was removed by incubating sections with $0.3 \% \mathrm{H}_{2} \mathrm{O}_{2}$ in PBS for $15 \mathrm{~min}$. Biocytin-labeled pyramidal neurons were revealed using an avidin-biotin complex method. Briefly, sections were incubated with an avidin-biotin complex (1:1000; avidin + biotinylated horseradish peroxidase; Vector Laboratories, Burlingame, CA) at room temperature for $1 \mathrm{hr}$. After incubating the sections in a mixture of $0.06 \% \mathrm{DAB}, 0.025 \%$ cobalt chloride, and $0.02 \%$ nickel ammonium sulfate in PBS $+\mathrm{T}$ for $15 \mathrm{~min}, \mathrm{H}_{2} \mathrm{O}_{2}$ was added, and the reaction was allowed to proceed for 1-2 min. After washing in PBS $+\mathrm{T}$, all sections were mounted on gelatin-coated glass slides, air-dried, dehydrated in ascending concentrations of ethanol, cleared with xylene, and coverslipped with Entellan (Merck, Darmstadt, Germany).

Before revealing the identity of labeled pyramidal neurons, they were reconstructed by a separate investigator using a camera lucida (Leica, Nussloch, Germany). Briefly, dendritic structures from three to four $100-$ $\mu \mathrm{m}$-thick sections were drawn with a $25 \times$ objective. These drawings were stored in a digital format for morphometric analysis using a M4 image analysis system (Imaging Research, St. Catharines, Ontario, Canada). The number of branches and total length of dendrites in four compartments, basal dendrites, oblique dendrites, apical dendrites, and dendritic tufts, were compiled. Basal dendrites were further subdivided into different orders to test for differences in branching pattern. In addition, a modified Sholl analysis for studying the dendritic density of basal and oblique dendrites was used. Briefly, concentric circles ranging from a radius of $10-200 \mu \mathrm{m}$ (in $10 \mu \mathrm{m}$ increments) were drawn from the cell body. The number of intersections between these circles and dendritic structures were measured. Finally, the size of cell bodies was compared.

For comparing dendritic spines, the number of spines on five $50-\mu \mathrm{m}$-long terminal branches from basal and oblique dendrites, as well as dendritic tufts of each neuron were counted under a $100 \times$ oil immersion objective. Terminal regions were chosen because they have been shown to be more sensitive to age-related insults (Buell and Coleman, 1979). The density of dendritic spines was expressed as the number of spines per $10 \mu \mathrm{m}$ of dendrite.

Ultrastructural quantification of presynaptic terminal density. Five young and five aged labeled pyramidal neurons were studied under an electron microscope to measure the density of appositions of synaptic structure on the labeled cells as previously described (De Koninck et al., 1992; Ma et al., 1996). Brain slices were processed for the demonstration of the labeled cell almost as described above except no Triton X-100 was put into PBS. Resectioned slices were then osmicated, dehydrated in ascending alcohols and propylene oxide, and finally flat-embedded in Epon (Meca Lab). The labeled neurons were photographed and reconstructed with a camera lucida from the flat embedded slices. Samples of the different portions of the labeled neuron (cell body and basal dendrites) were selected and re-embedded in Epon blocks. Subsequently, 4- $\mu$ m-thick plastic sections were cut serially with an ultramicrotome (Reichert-Jung), photographed and compared with the original drawings to identify the parts of the labeled neuron present in each section. The selected 4- $\mu \mathrm{m}$-thick sections were then re-embedded in Epon, and ultrathin sections were cut, collected onto one-slot formvar-coated grids, counterstained with uranyl acetate and lead citrate, and finally, observed with a Philips 410 LS electron microscope. For each cell, the total number of boutons, both synaptic and nonsynaptic, apposed to proximal and distal dendrites and the cell body was counted on the electron microscope screen at a high magnification $(17,700 \times)$. Subsequently, the entire studied field was photographed at a low magnification $(4400 \times)$ for measuring the length of cell membrane to which boutons were apposed using an image analysis system (MCID-M4 system; Imaging Research). At least five fields of the three studied compartments from each labeled cell were studied. The densities of boutons per $100 \mu \mathrm{m}$ of postsynaptic membrane were obtained for each labeled neuron.

Statistics. Student's $t$ tests were used to analyze the differences in morphological parameters between aged and young rats. Nonparametric Mann-Whitney $U$ tests were used for differences in physiological parameters. The critical value for statistical significance was set at $p<0.05$. All data are expressed as mean \pm SEM. 
Table 1. Age spectrum of the $\mathrm{BNxF344} \mathrm{F}_{1}$ hybrid rats used in the present study

\begin{tabular}{llr} 
Age group & $\begin{array}{l}\text { Age } \\
(\text { months })\end{array}$ & $n$ \\
\hline Young $($ mean $=1.8 \pm 0.1)$ & 1 & 5 \\
Aged $($ mean $=31.9 \pm 0.4)$ & 2 & 18 \\
& 29 & 6 \\
& 31 & 4 \\
& 32 & 3 \\
& 33 & 7 \\
\hline
\end{tabular}

\section{RESULTS}

\section{Population of cells studied}

A total of 198 layer $\mathrm{V}$ neurons were recorded from 23 young adult (1- to 2-month-old) and 25 aged (29- to 37-month-old) BNxF344 $\mathrm{F}_{1}$ hybrid rats (Table 1). From these cells, 128 were successfully labeled, and 95 of them were morphologically identified as pyramidal neurons. The criteria used to identify the cells as pyramidal neurons were a triangular-shaped cell body with dendritic structures composed of basal dendrites, oblique dendrites, and an apical dendrite (Feldman, 1984; De Felipe and Farinas, 1992). However, only 69 from these 95 neurons were selected for both morphological and physiological analyses based on the following criteria. First, only cells with stable access resistance $(12.3 \pm 0.5 \mathrm{M} \Omega)$ throughout the recording were used. In addition, recordings with unstable membrane currents were discarded. Finally, only neurons with a resting membrane potential between -60 and $-70 \mathrm{mV}$ were selected. Figure 1 shows representative examples of two pyramidal neurons from a young and an aged rat after reconstruction. From these 69 pyramidal neurons, 34 were recorded from young rats and 35 from aged rats. No significant differences were found for the resting membrane potential $(-63.8 \pm 0.9$ vs $-62.5 \pm 1.7 \mathrm{mV})$, input resistance $(90.0 \pm 9.1$ vs $89.3 \pm 6.8 \mathrm{M} \Omega)$ between pyramidal neurons from the two age groups. A small, but not statistically significant decrease in membrane capacitance $(564.2 \pm 31.6$ vs $512.1 \pm 41.0 \mathrm{pF}$ ) was observed in the aged group.

\section{Significant reduction in the size of cell bodies and shortening of basal dendrites in aged rats}

Several morphometric parameters of layer V pyramidal neurons in the parietal cortex were significantly altered in the group of aged animals. The size of the cell body of pyramidal neurons in aged rats shrunk on average to $64 \%$ of the size of young cells in a twodimensional analysis $\left(392.1 \pm 25.1 \mu \mathrm{m}^{2}\right.$ in young vs $250.3 \pm 18.2$ $\mu \mathrm{m}^{2}$ in aged rats; $p<0.001$; Fig. $1 C$ ). With respect to the total number of basal dendritic branches, pyramidal neurons from aged animals also possessed significantly fewer branches than those from young rats $(60.8 \pm 3.2$ in young vs $39.5 \pm 3.9$ in aged rats; $p<0.05$; Fig. $2 A$ ). Consequently, the total length of basal dendrites was also significantly decreased in aged rats $(3952.0 \pm 139.0 \mu \mathrm{m}$ in young vs $3020.2 \pm 279.5 \mu \mathrm{m}$ in aged rats; $p<0.05$; Fig. $2 B$ ). Figure $2 C$ illustrates quantification of the branching pattern of basal dendrites for the two age groups. We also found a significant age-related decrease in the number of high-order distal basal dendritic branches, including fourth $(14.7 \pm 0.9$ in young vs $11.5 \pm 1.1$ in aged rats; $p<0.05)$, fifth $(10.2 \pm 1.6$ in young vs $4.3 \pm 0.8$ in aged rats; $p<0.01)$, and sixth order branches $(6.2 \pm 1.1$ in young vs $1.0 \pm 0.8$ in aged rats; $p<0.01)$. Furthermore, no seventh and eighth order branches were found for the basal dendrites of pyra-
A

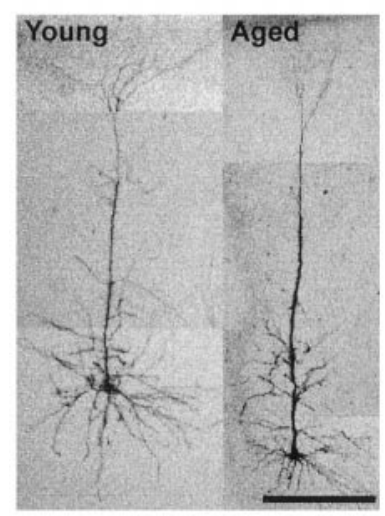

C

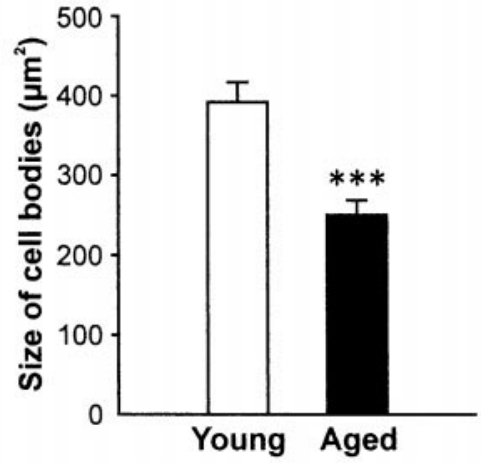

B
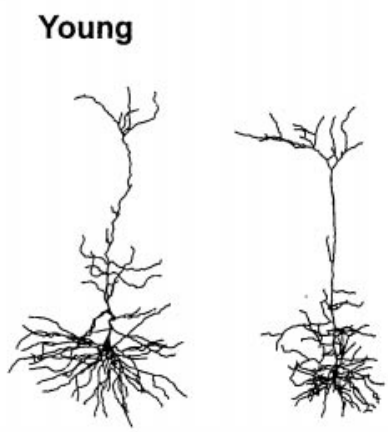

Aged
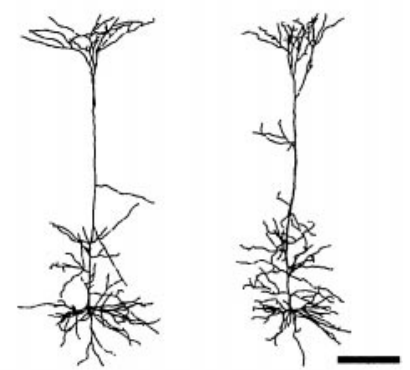

Figure 1. Reconstruction of representative labeled layer V pyramidal neurons from young and aged rats. $A$, Photomicrographs of labeled layer $\mathrm{V}$ pyramidal neurons from young and aged rats. Note the obvious age-related alteration of dendrites of the neuron taken from the aged (33-month-old) rat when compared with that of the neuron from the young (2-month-old) rat. Scale bar, $200 \mu \mathrm{m}$. $B$, Representative camera lucida reconstructions of two young and two aged layer V pyramidal neurons. Scale bar, $200 \mu \mathrm{m}$. $C$, Significant reduction in cell body size of pyramidal neurons in the aged neocortex. The cross-section area of pyramidal cell bodies from aged rats is significantly smaller than that from young rats $(* * * p<0.001)$.

midal neurons in aged rats, whereas those values were $2.2 \pm 0.9$ for seventh order branches and $0.67 \pm 0.5$ for eighth order branches in young rats. Sholl analysis revealed fewer intersections between basal dendrites and concentric circles at all distances (10-200 $\mu \mathrm{m})$ from the cell body, indicating lower density of basal dendrites at all distances in aged rats (Fig. 2D). The density of basal dendrites in both age groups reached their minimal values at $200 \mu \mathrm{m}$, and no significant difference in the radial coverage of basal dendrites between the two age groups was found. In addition, a similar decrease (approximately five intersections fewer in aged rats) of dendritic density was found at all distances, implying a uniform loss of branches throughout the basal dendritic field of pyramidal neurons in aged rats. Parallel to the loss of basal dendrites, the density of spines on these dendrites was significantly lower in aged rats $(7.6 \pm 1.0$ spines $/ 10 \mu \mathrm{m}$ of membrane length in young vs $2.8 \pm 0.3$ spines $/ 10 \mu \mathrm{m}$ of membrane length in aged rats; $p<$ 0.001 ; Fig. 3).

\section{Dendritic components other than basal dendrites}

In contrast to basal dendrites, no statistically significant difference was found in the number of branches for oblique dendrites in young and aged rats (Fig. 4A). In addition, there was also no difference in the length of oblique dendrites between the two age groups (Fig. $4 B$ ). Finally, results from Sholl analysis of oblique dendrites also 

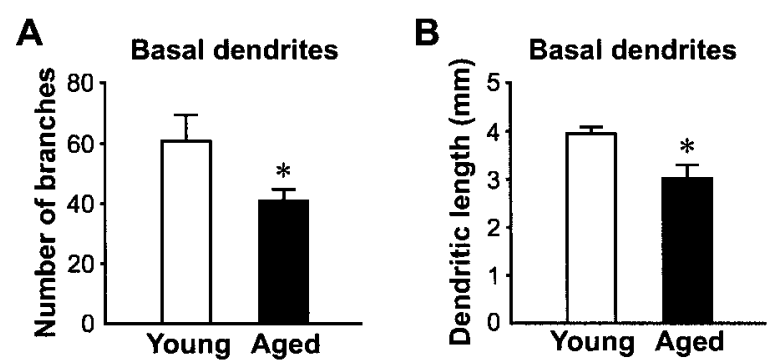

C

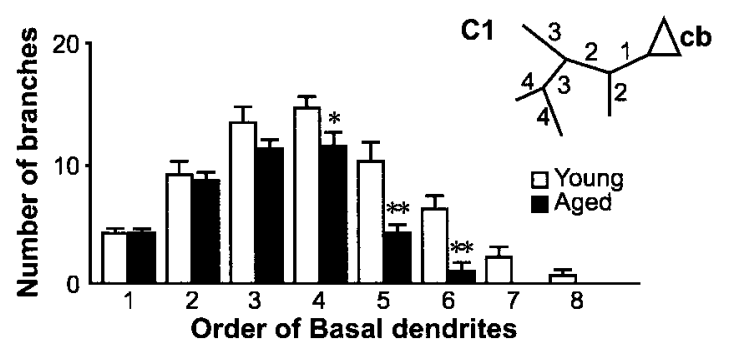

D

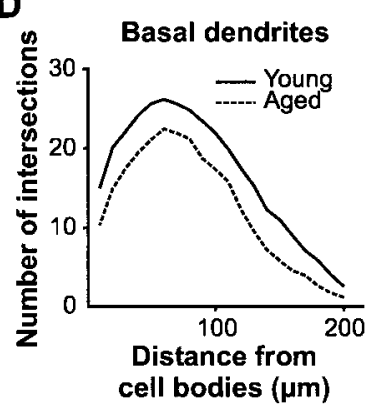

E

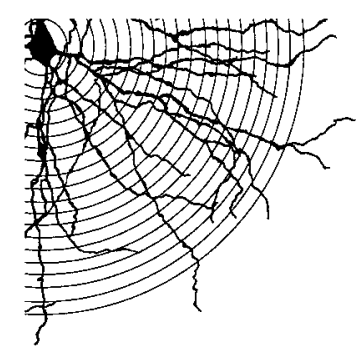

Figure 2. Significant shortening of basal dendrites of layer $\mathrm{V}$ pyramidal neurons with aging. $A$, Comparison of the number of branches from basal dendrites between young and aged pyramidal neurons revealed a significant loss of branches in pyramidal neurons of aged brains $\left({ }^{*} p<0.05\right) . B$, Because of this decrease in branching, a notable reduction of total basal dendrites length was found $\left({ }^{*} p<0.05\right)$. $C$, Basal dendrites were further divided into different branching orders following the scheme described in the insert ( $C 1, c b$, cell body; number represented different branch orders). Significant age-related decreases were found for the number of fourth order $\left({ }^{*} p<0.05\right)$, fifth order $\left({ }^{* *} p<0.01\right)$, and sixth order $\left({ }^{* *} p<0.01\right)$ basal dendritic branches. Furthermore, virtually no seventh order and eighth order basal dendrites were found in aged pyramidal neurons. This illustrated a significant loss of high-order basal dendritic branches in the aged brain. $D$, Results from a Sholl analysis also illustrated an age-related decline in the density of basal dendrites. The number of intersections of these dendrites with concentric circles placed at increasing intervals $(10-200 \mu \mathrm{m}$; $10 \mu \mathrm{m}$ increments) from the cell body was lower in aged pyramidal neurons than in young rats at all distances $(E)$. However, no change in the pattern of basal dendritic density was found in aging. Thus, these results indicate that basal dendrites from both young and aged rats covered similar radial distances, but that aged rats had fewer dendritic branches.

revealed no age-related difference (Fig. $4 C$ ). Although dendrites in the tuft region possessed significantly more branches in aged rats $(16.4 \pm 1.3$ in young vs $44.8 \pm 3.8$ in aged rats; $p<0.001)$, no significant increase in the total length of dendrites in the tuft region was reached in aged rats (Fig. $4 B$ ). Nevertheless, significant agerelated decreases in the density of dendritic spines were found in both oblique dendrites $(6.8 \pm 0.9$ in young vs $3.6 \pm 0.5$ spines/10 $\mu \mathrm{m}$ of membrane length in aged rats; $p<0.05$; Fig. 3 ), and dendritic tufts $(5.6 \pm 0.2$ in young vs $3.3 \pm 0.8$ spines $/ 10 \mu \mathrm{m}$ of membrane length in aged rats; $p<0.05)$. Finally, similar lengths for the apical dendrites were found in both young and aged animals $(527.8 \pm 17.3$ in young vs $595.6 \pm 39.3 \mu \mathrm{m}$ in aged rats; $p=0.26$; Fig. 4D).
A
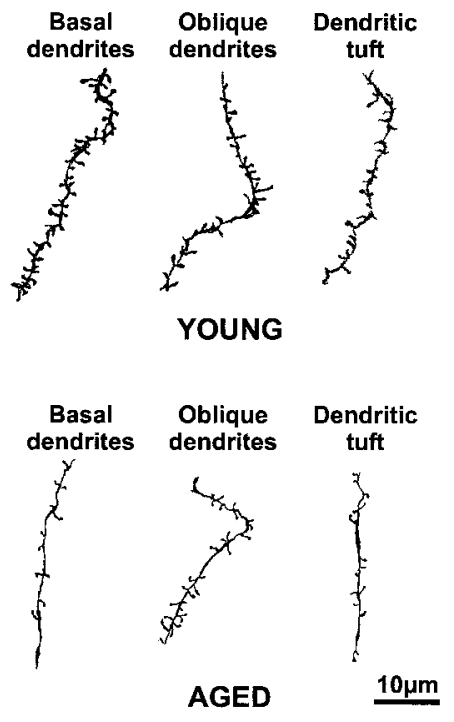

$\mathbf{B}$

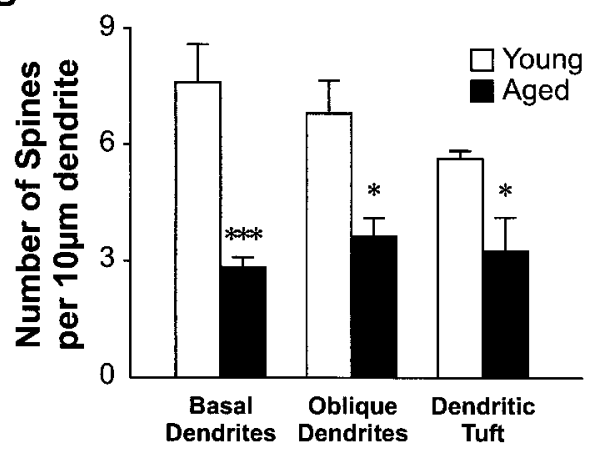

Figure 3. Significant loss of dendritic spines with aging. $A$, Drawings represent camera lucida-reconstructed terminal dendritic segments of different dendritic regions from both young and aged animals. Note the striking differences in terms of spine density and dendritic thickness between these two aged groups. Scale bar, $10 \mu \mathrm{m}$. $B$, Histogram illustrating the difference in the spine density in different dendritic regions between young and aged neurons. Significant reduction in spine density was found for basal dendrites $(* * * p<0.001)$, oblique dendrites $\left({ }^{*} p<0.05\right)$, and dendritic tuft $\left({ }^{*} p<0.05\right)$.

\section{Fewer presynaptic contacts on pyramidal neurons in aged rats}

The reduction in number of dendritic branches in aged pyramidal cells may limit postsynaptic substrate for synaptic connections. Yet, we have also recently shown that the density of presynaptic boutons in deep layers of the parietal cortex was reduced in aged brains (Wong et al., 1998). This finding therefore raises the additional question of whether the density of presynaptic boutons per unit length of dendrites is altered in aged pyramidal neurons. To determine this, we performed ultrastructural quantification of the number of presynaptic boutons in five young and five aged labeled pyramidal cells. Analyses were applied to both the cell body region and basal dendrites. Figure 5 shows examples of presynaptic contacts on an intracellularly labeled pyramidal neuron.

Quantification of presynaptic boutons density revealed a significant loss of presynaptic inputs in the cell body region $(12.7 \pm 0.4$ vs $7.9 \pm 0.4 / 100 \mu \mathrm{m}$ of postsynaptic cell membrane in young and aged rats, respectively; $p<0.01$; Fig. $5 D$ ), as well as on basal dendrites $(17.8 \pm 1.3$ vs $13.5 \pm 0.4 / 100 \mu \mathrm{m}$ of postsynaptic cell membrane in young and aged rats, respectively; $p<0.01$ ) in aged rats. Thus, in addition to a decrease in available postsynaptic structures because of trimming of dendrites and spines of layer $\mathrm{V}$ pyramidal neurons, the decrease in density of boutons per unit 
Oblique dendrites and Dendritic tuft

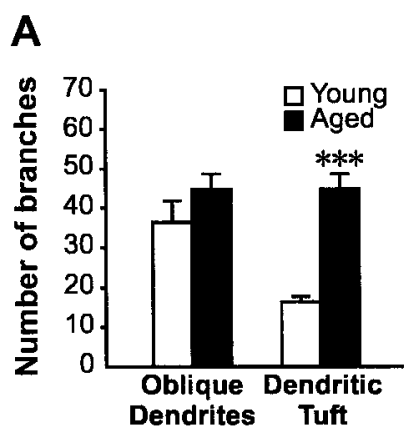

B
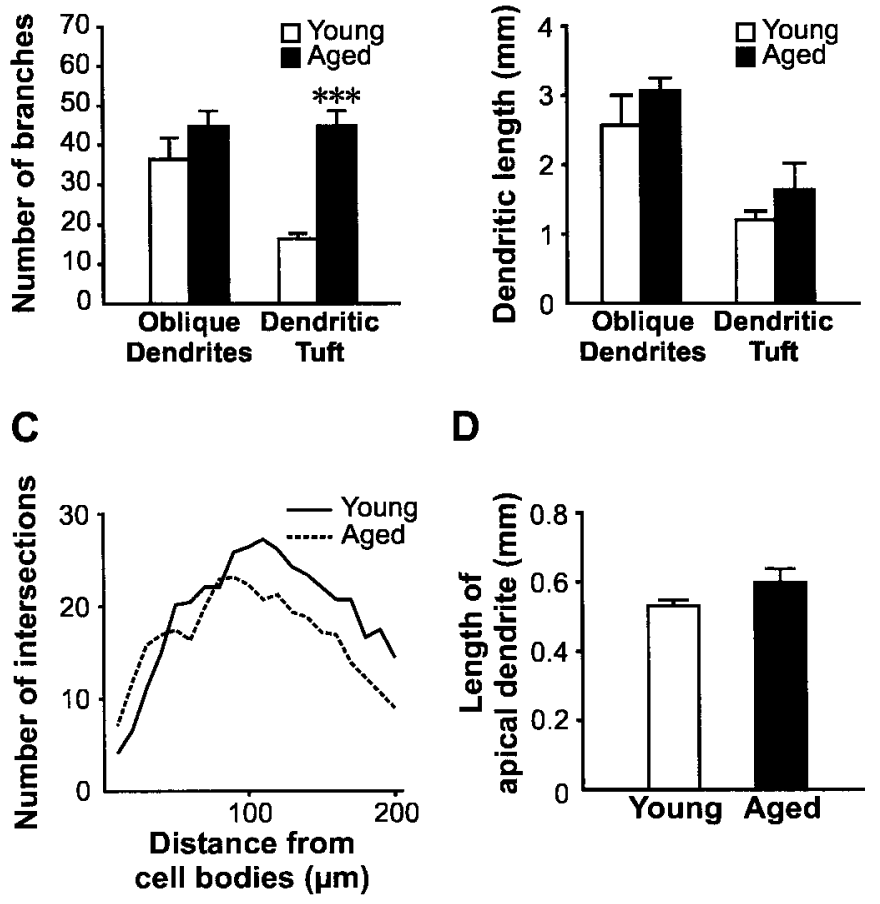

Figure 4. No reduction in dendrite length or branches in branching patterns in other dendritic regions of layer $\mathrm{V}$ pyramidal neurons with aging. $A$, Comparison of the number of branches from the tuft region revealed a significant increase in aged rats $(* * * p<0.001)$. However, similar changes were not found when comparing oblique dendrites between these two age groups. $B$, No significant difference in the length of oblique dendrites and tufts were found. This finding illustrated an increase in branching, but not dendritic structures, of apical tufts in pyramidal neurons of the aged brain. $C$, Results from a Sholl analysis indicated a nonsignificant increase in number of oblique dendrites in aged rats. This increase started at $50 \mu \mathrm{m}$ away from the cell body and continued with increasing distances. $D$, Comparison of the length of apical dendrites between young and aged pyramidal neurons revealed no significant difference.

length of dendrites further decreases the amount of available synapses onto these cells.

\section{Comparable frequency of spontaneous PSCs in aged layer $\mathbf{V}$ pyramidal neurons}

Given the marked shortening of dendrites and decrease in density of presynaptic boutons in layer $\mathrm{V}$ pyramidal neurons, one would expect a comparable reduction in synaptic input bombarding those neurons. To test this we quantified the level of spontaneous PSCs. Thirty-seven (18 young and 19 aged) of the 69 selected pyramidal neurons were recorded for sufficient duration to obtain data on sPSCs. For the remaining 32 (15 young and 17 aged) pyramidal neurons mPSCs (action potential-independent) were recorded. Representative traces and distribution of amplitude, 10-90\% rise time, and decay time constant of both sEPSCs and sIPSCs are shown in Figure 6.

To determine whether the functional synaptic inputs were modified in aged rats after the reported loss of synaptic substrate, we measured the frequency of both sEPSCs and sIPSCs. Despite the drastic reduction in synaptic substrate in aged rats, no difference in the frequency of either sEPSCs or sIPSCs was found between young and aged rats (Fig. 7). Comparison of the amplitude of sIPSC s between these two animal groups also revealed no difference (Fig. 8). A significant decrease of sEPSC amplitude was however observed in aged rats $(28.2 \pm 1.7$ in young vs $21.7 \pm 1.9 \mathrm{pA}$ in aged rats; $p<0.05$; Fig. 8$)$.
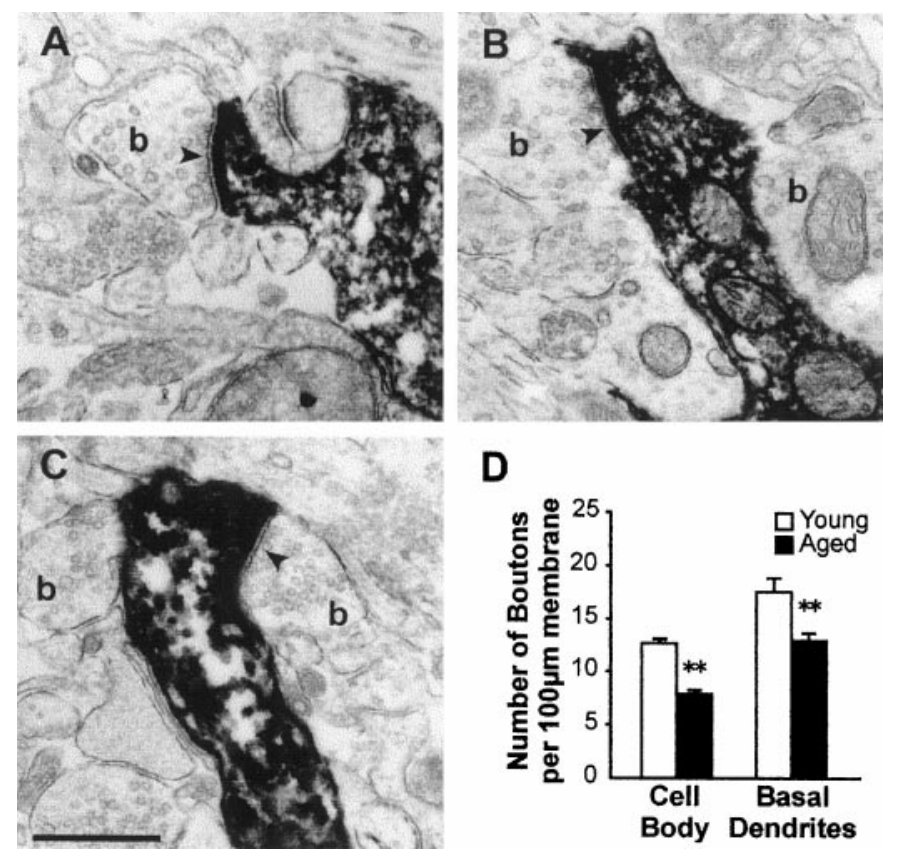

Figure 5. Age-related loss of presynaptic terminals on identified layer $\mathrm{V}$ pyramidal neurons. $A-C$, Electron micrographs illustrating appositions of presynaptic boutons $(b)$ on dendrites of an intracellularly labeled pyramidal neuron. Note the presence of numerous agranular synaptic vesicles in the boutons. The existence of synapses (arrowheads) between the boutons and of the labeled cell was revealed by the postsynaptic clustering of agranular vesicles and the presence of a synaptic cleft. Scale bar, $0.5 \mu \mathrm{m}$. D, Histogram shows the density of bouton appositions on cell bodies and basal dendrites. A significantly lower number of presynaptic contacts per unit length of postsynaptic membrane were found in both the cell body region and basal dendrites of aged rats $(* * p<0.01)$.

A change in electrotonic properties of the cells could have resulted in different space-clamp attenuation of sPSCs between the two cell populations and thus affect the amplitude measurements and detection of the events (for review, see Rall and Segev, 1985; Spruston et al., 1994). To control for this possibility, we compared the kinetic properties of sEPSCs and sIPSCs in both aged groups. The decay phase of both sEPSCs and sIPSCs were adequately described by a monoexponential function, consistent with previous reports (for example, see Salin and Prince, 1996). No significant difference in decay time constant of sEPSCs $(3.3 \pm 0.3 \mathrm{msec}$ in young vs $3.6 \pm 0.2 \mathrm{msec}$ in aged rats; $p=0.35)$ or sIPSCs $(5.7 \pm 0.8$ msec in young rats vs $5.5 \pm 0.6 \mathrm{msec}$ in aged rats; $p=0.82$ ) were found between the two age groups (Fig. 8). These findings are consistent with the lack of change in capacitance of pyramidal neurons from the two aged groups (564.2 \pm 31.6 in young vs 512.1 $\pm 41.0 \mathrm{pF}$ in aged rats), lack of change in input resistance $(90.0 \pm$ 9.1 in young vs $89.3 \pm 6.8 \mathrm{M} \Omega$ in aged rats), and thus membrane time constants $(3.9 \pm 0.3$ in young vs $3.6 \pm 0.3 \mathrm{msec}$ in aged rats). We also compared the $10-90 \%$ rise time of sPSC between the two groups of cells. As for the decay time constant, no difference in the rise time of either sEPSC $(1.0 \pm 0.07$ in young vs $1.1 \pm 0.05 \mathrm{msec}$ in aged rats; $p=0.08)$ or sIPSC $(1.2 \pm 0.1$ in young vs $1.4 \pm 0.3$ msec in aged rats; $p=0.4$ ) in young and aged rats were found (Fig. $8)$. Thus, the lack of difference in rising kinetics of the sPSCs indicates that the events originated at similar electrotonic distance from the soma of the recorded neurons in both age groups.

\section{Decrease in action potential-independent (miniature) PSCs in aged rats}

The sPSCs we recorded correspond to the sum of two types of synaptic activity. One is resistant to TTX and corresponds to the action potential-independent spontaneous release of neurotransmitter at synapses (referred to as miniature synaptic activity; Fig. 9, insert), the other type of activity reflects the level of spontaneous action potential firing in neurons presynaptic to the recorded cell 


\section{A sEPSCs}

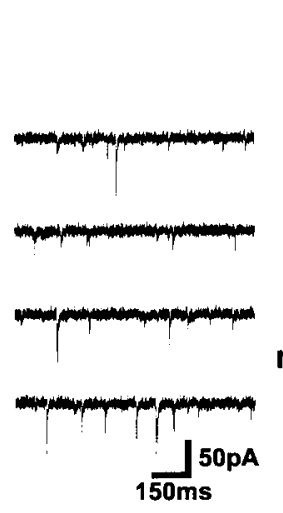

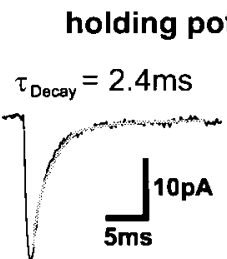

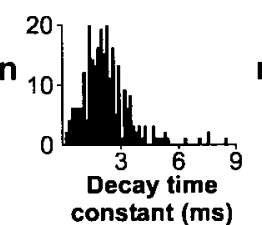

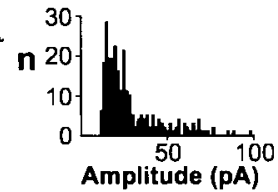

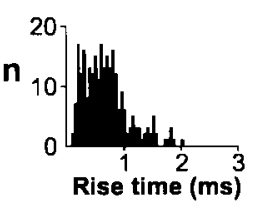

\section{B sIPSCs}

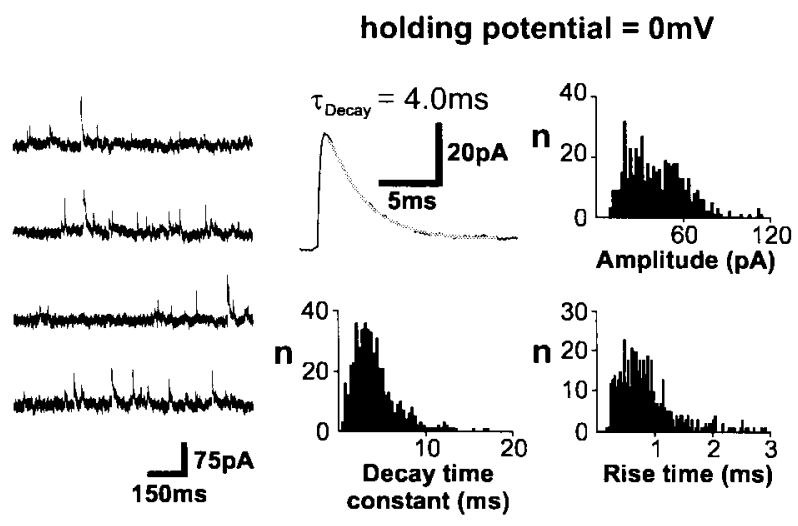

Figure 6. Characterization of spontaneous EPSCs and IPSCs in layer V pyramidal neurons. A, Consecutive traces displaying spontaneous EPSCs

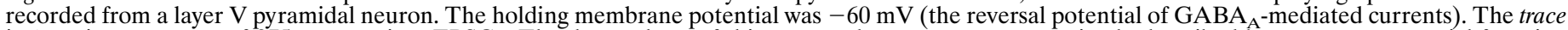
in inset is an average of 275 consecutive sEPSCs. The decay phase of this averaged current was appropriately described by a monoexponential function (decay time constant $\tau_{\mathrm{D}}=2.4 \mathrm{msec}$ ). Histograms illustrating the distribution of amplitude, $10-90 \%$ rise time, and decay time constant of sEPSCs in this neuron $(n=479)$. $B$, Consecutive traces illustrating spontaneous IPSCs recorded from the same layer V pyramidal neuron. The holding membrane potential was $0 \mathrm{mV}$ (the reversal potential of ionotropic glutamate receptor-mediated currents). The trace in inset is an average of 486 consecutive sIPSCs. The decay phase of this averaged current was fitted with a monoexponential function (decay time constant $\tau_{\mathrm{D}}=4.0 \mathrm{msec}$ ). The histograms illustrate the distribution of amplitude, $10-90 \%$ rise time, and decay time constant of sIPSCs in this neuron $(n=954)$.

A

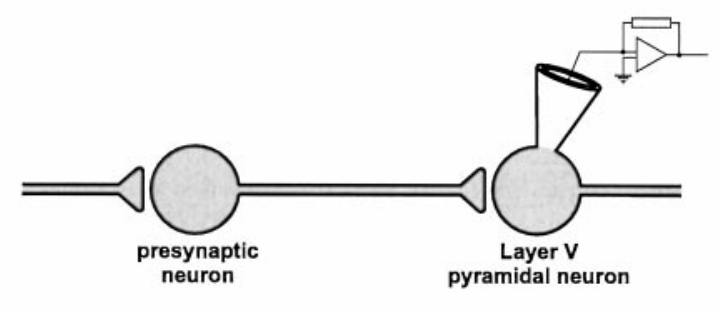

B sEPSCs

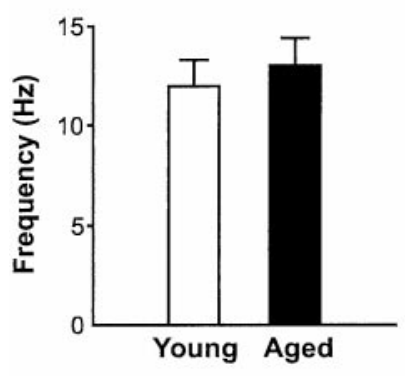

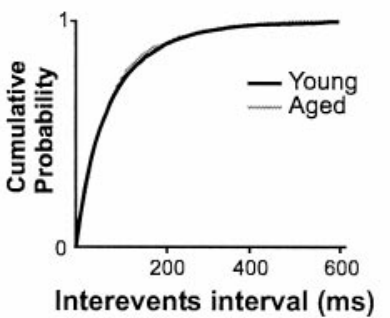

C SIPSCs
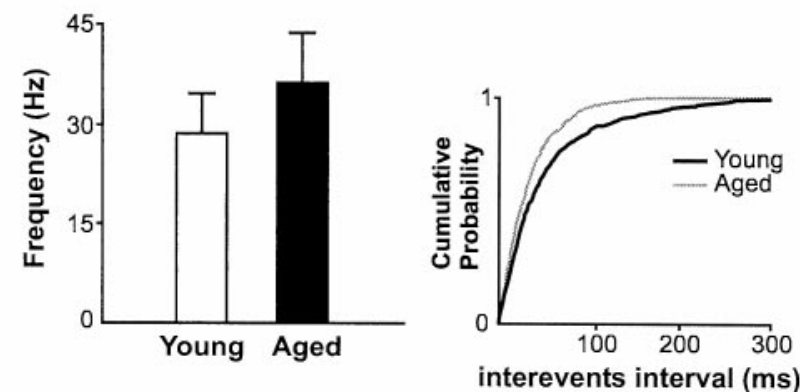

Figure 7. No reduction in the frequency of spontaneously occurring EPSCs and IPSCs. $A$, Schematic diagram showing the type of activity reflected by SPSCs recorded in layer V pyramidal neurons (contrast with Fig. $9 A$ ). These sPSCs result from the sum of both the intrinsic releasing properties of the synaptic terminal and the action potential firing activity in neurons presynaptic to the recorded cell. $B, C$, Histograms show the frequency of both sEPSCs and sIPSCs from young and aged rats. The cumulative probability plots on the right of each histogram further illustrate the modification in the distribution of frequency for both sEPSCs and sIPSCs with aging. These plots were constructed by adding equal sets of 100 consecutive sPSCs taken from each neuron in both age groups (i.e., 1800 events in young and 1900 events in aged animals).

(Fig. 7, insert). To determine whether the reduction in synaptic substrates in aged rats result in a loss of miniature activity (reflecting the number of functional boutons in contact with the pyramidal neuron), we compared properties of both mEPSCs and mIPSCs in young and aged rats in all pyramidal neurons. The mean $10-90 \%$ rise times of mEPSCs and mIPSCs were $1.0 \pm 0.1$ and $1.4 \pm 0.3$ msec, respectively. Similar to sPSCs, the decay phase of these spontaneously occurring mPSCs was adequately described by a monoexponential function (Salin and Prince, 1996).

In contrast to the findings with sPSCs, a significant decrease in frequency of both mEPSCs $(3.3 \pm 0.5 \mathrm{~Hz}$ in young vs $2.2 \pm 0.5 \mathrm{~Hz}$ in aged rats; $p<0.05$; Fig. $9 A)$ and mIPSCs $(9.6 \pm 1.4 \mathrm{~Hz}$ in young 


\section{A SEPSCs}
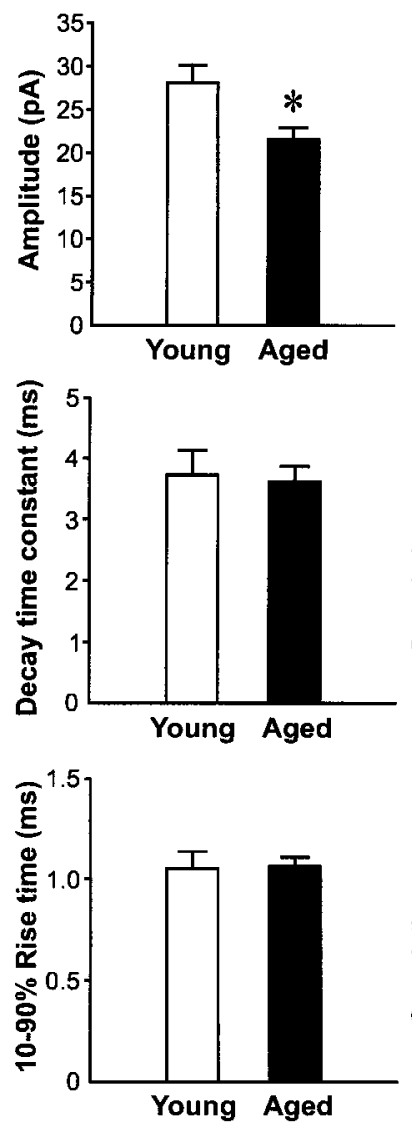
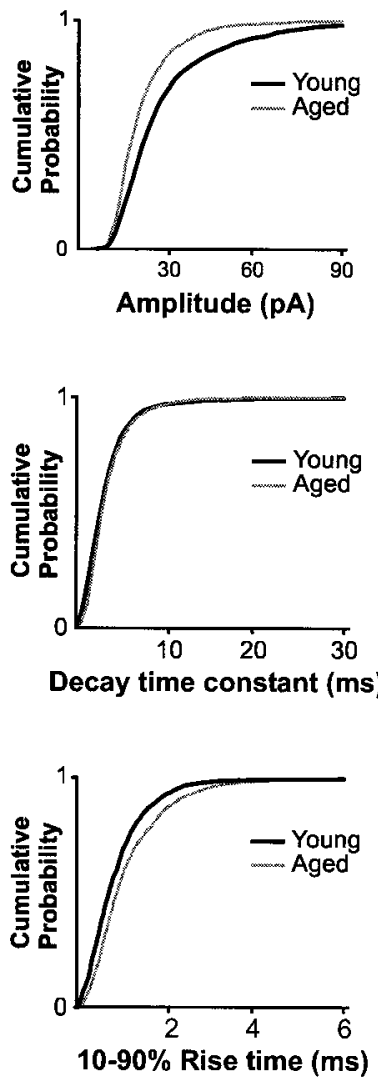

\section{B sIPSCs}
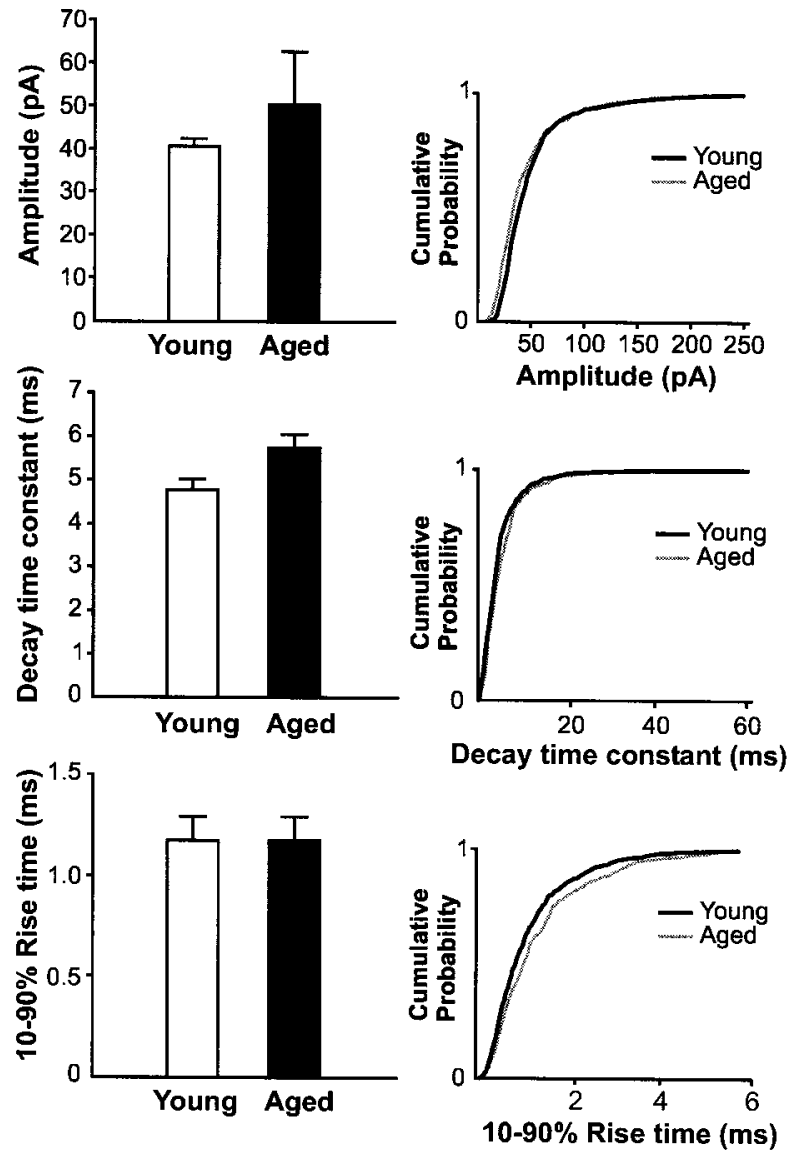

Figure 8. Lack of change in the kinetic parameters of sEPSCs and sIPSCs in aged rats. Histogram showing the amplitude, 10-90\% rise time, and the decay time constant of both sEPSCs and sIPSCs from young and aged rats. Apart from a significant lower amplitude of sEPSC in aged rats $(* p<0.05)$, no difference in kinetic parameters between the two age groups was found $(p>0.1)$. The cumulative probability plots on the right of each histogram further illustrate the lack of change in the distribution of these parameters for both sEPSCs and sIPSCs with aging. These plots were constructed by adding equal sets of 100 consecutive sPSCs taken from each neuron in both age groups (i.e., 1800 events in young and 1900 events in aged animals).

vs $6.1 \pm 1.0 \mathrm{~Hz}$ in aged rats; $p<0.05$; Fig. $9 B$ ) was found in aged rats. Interestingly, a similar relative decrease for both mEPSC (33.3\% decrease) and mIPSC (36.7\% decrease) frequency was found. No difference in mEPSC nor mIPSC amplitude, decay time constant, or rise time was observed between the two aged groups (Fig. 10), indicating no change in electrotonic filtering of the events.

\section{Increase in action potential-dependent PSCs in aged rats}

Unlike mPSCs, which result from action potential-independent spontaneous release of vesicles from synaptic terminals, the frequency of sPSCs recorded in absence of TTX represents the sum of TTX-insensitive mPSCs and TTX-sensitive (action potentialdependent) PSCs. Given the decrease in mPSC frequency, the comparable frequency of sPSCs in both age groups therefore suggests a rise in the action potential dependent, or driven activity (frequency $_{\mathrm{sPSC}}-$ frequency $_{\mathrm{mPSCs}}$; Figs. 7, 9, inserts) in the aged rats.

\section{DISCUSSION}

In the present study, we have identified a number of alterations in the morphology of, and the structural and functional synaptic input to, layer $\mathrm{V}$ pyramidal neurons in aged rats. We found a significant reduction in the size of cell body in aged rats. We also observed a significant shortening of total length of basal dendrites in aging, which was the result of a decrease in the number of branches but not the radial extent of the basal dendritic tree. In addition, we showed a drastic loss of dendritic spines in all studied dendritic regions. Finally, a significant decrease in density of presynaptic boutons (per unit length of postsynaptic membrane) in contact with the pyramidal cells was also observed in aged rats. Parallel to these structural deficits in aged brain, we observed a matching decrease in the frequencies of both action potential-independent mEPSCs and mIPSCs without any difference in the amplitudes and kinetic properties of these synaptic events. Although these findings would suggest a decrease in basal synaptic inputs to layer $\mathrm{V}$ pyramidal neurons of the parietal cortex, we also observed comparable frequencies of sEPSCs and sIPSCs in both young and aged rats. These results therefore suggest an increase in action potential-dependent PSCs, possibly reflecting a compensatory increase in driven activity from the network of neurons presynaptic to layer $\mathrm{V}$ pyramidal neurons counterbalancing the significant loss of synaptic substrate in the aged brain.

\section{Reductions in cell body sizes and dendrites of layer $\mathbf{V}$ pyramidal neurons in aged rats}

This is the first study that uses an intracellular labeling technique to examine the modification of pyramidal neurons in aged rats. This method allows us to fill dendrites of recorded cell completely for dendritic morphometry as with the conventional Golgi method. The rather simple staining procedures of this labeling method also 


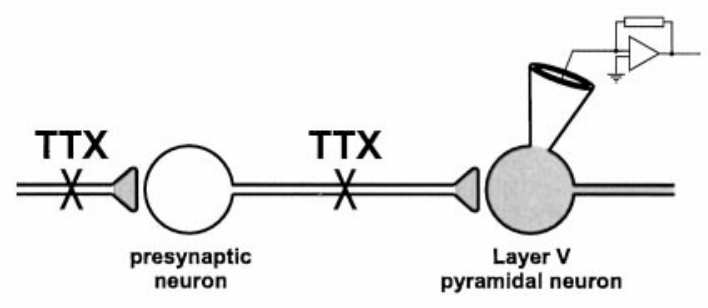

B mEPSCs

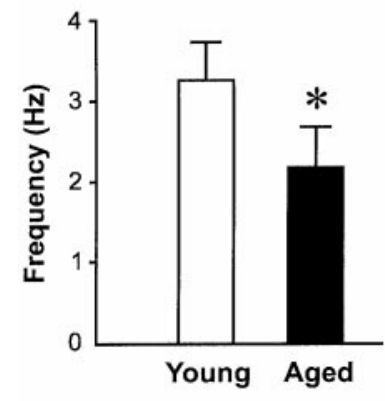

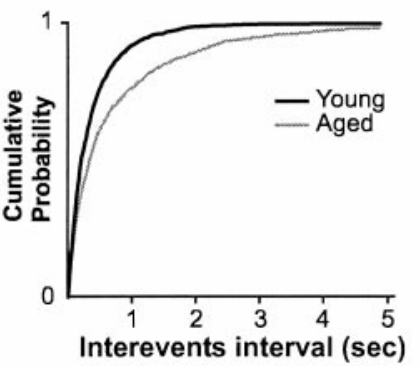

C mIPSCs

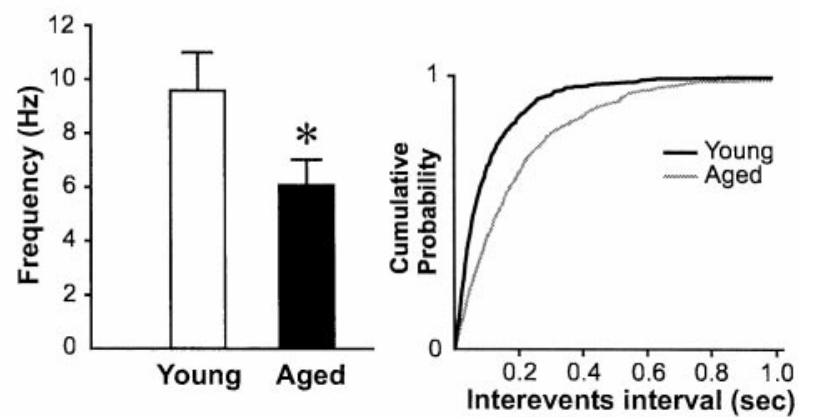

Figure 9. Significant reduction in the frequency of both action potential-independent mEPSCs and mIPSCs in cortical pyramidal neurons of aged rats. $A$, Schematic diagram showing the type of activity reflected by mPSCs recorded from layer $\mathrm{V}$ pyramidal neurons (contrast with Fig. $7 A$ ). The propagation of action potential being blocked by addition of $1 \mu \mathrm{M}$ tetrodotoxin $(T T X)$ in the bathing solution, the mPSCs correspond only to action potential independent spontaneous release of neurotransmitter from synaptic terminals effectively uncoupled from the soma-dendritic region of the presynaptic cell. $B$, Histogram displaying the significant $33.3 \%$ decrease in the frequency of mEPSCs in aged rats $\left({ }^{*} p<0.05\right)$. $C$, Similar significant $36.7 \%$ decrease in the frequency of mIPSCs in aged rats $\left({ }^{*} p<0.05\right)$. The graphs on the right are cumulative probability plots of interevent intervals further illustrating the decrease in frequency of mPSCs in aged rats. These plots were constructed by adding equal sets of 100 consecutive mPSCs taken from each neuron (1500 events in young and 1700 events in aged animals).

results in well preserved tissue quality and makes ultrastructural observation of synaptic input to labeled cells possible. In fact, this labeling method has been shown to have several advantages over the conventional Golgi method (for review, see Larkman, 1991).

Examination of aged pyramidal neurons revealed several unique modifications. We found that the loss of basal dendrite length is mainly attributable to the disappearance of high-order basal dendritic branches but not a shortened radial coverage. However, we still observed a robust reduction in cell body size $(34 \%)$ in aged rats. This finding, together with the loss of neuropil reported in the present study, is parallel to the reported significant age-related shrinkage of pyramidal neuron in human studies (Koenderink et al., 1994; de Brabander et al., 1998). This significant reduction of soma size may account for the prominent shrinkage of cortical tissue in normal aging (Jack et al., 1998; Fox et al., 1999) and Alzheimer's disease (Fox et al., 1996). It is also of particular interest to note that the preferential loss of basal dendrites matches the more prominent age-related loss of synaptic substrates in deep cortical layers (Wong et al., 1998; de Brabander et al., 1998).

One of the possible causes of a decrease in dendritic spines may be the loss of presynaptic terminals. McKinney et al. (1999) have shown that blocking ongoing AMPA-receptor mediated EPSCs by botulinum toxin in hippocampal slice culture caused a decrease in the density of spines in CA1 pyramidal neurons. In contrast, no change in spine density was found when incubating the slice culture with TTX. This finding suggested that spontaneous miniature (action potential-independent) glutamate release from synaptic terminals is sufficient for the maintenance of the spine population.

\section{Functional compensation for the decrease in synaptic structures}

It is of particular interest to note that, despite a profound loss of dendritic spines, we did not find a preferential decrease in the frequency of mEPSCs versus that of mIPSCs in aged brain. The age-related decrease in the frequency of mIPSCs (37\%) is consistent with the reduction in the surface area of cell body, which appear to be the primary target of inhibitory GABAergic synapses (White, 1989; Soltesz et al., 1995). This decrease is also parallel to declines in both mRNA level (Mhatre et al., 1991; Mhatre and

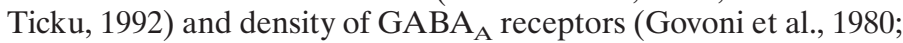
Kossut et al., 1991; Wenk et al., 1991; Post-Munson et al., 1994) in the aged cerebral cortex. Because most excitatory synapses appear to occur on dendritic spines (Feldman, 1984), the reduction in spine density is also consistent with the decrease mEPSC frequency. The net result is a maintenance of the balance between the two types of inputs.

In contrast to the decrease observed in mPSC frequency, no change in neither sEPSC nor sIPSC frequency was found in aged brains. This can be interpreted as indicating an increase in action potential-dependent input (i.e., an increase in the ratio of sPSC frequency to mPSC frequency) and thus an increased activity in neurons that are presynaptic to pyramidal neurons in aged animals. Several lines of evidence indicate that this increase in synaptic inputs is well regulated. For instance, both sEPSC and SIPSC frequency in aged rats were maintained at a comparable level to that in young animals. In addition, the ratio of the frequency of sEPSCs and sIPSCs was similar in both age groups. Given that the balance of inhibition and excitation may play an important role in 


\section{A mEPSCs}
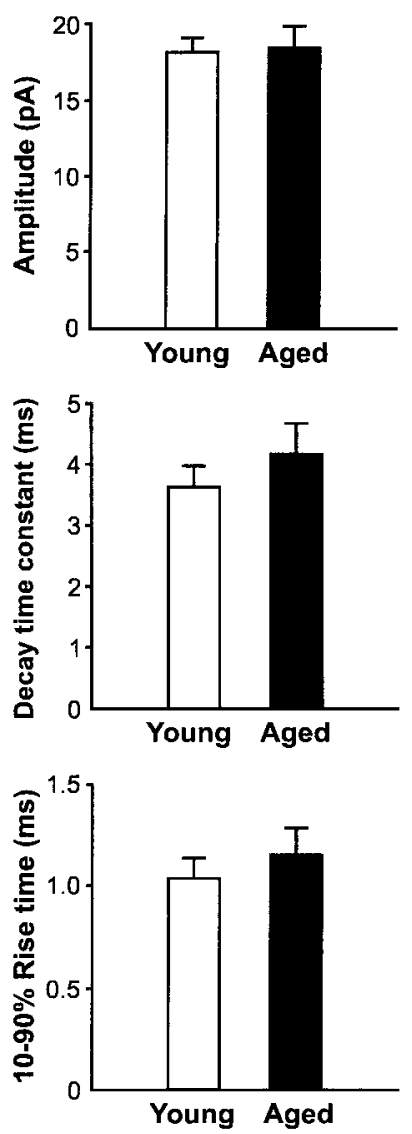
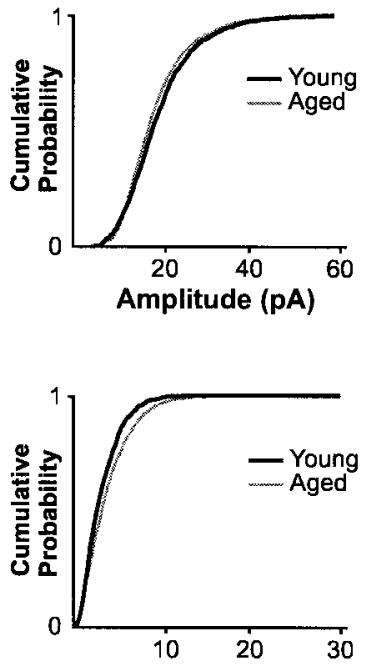

Decay time constant (ms)

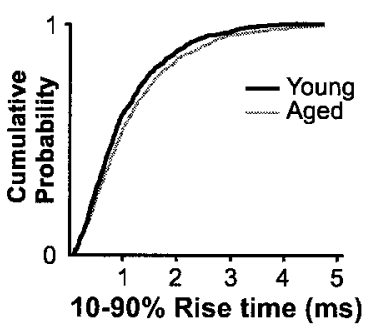

\section{B mIPSCs}
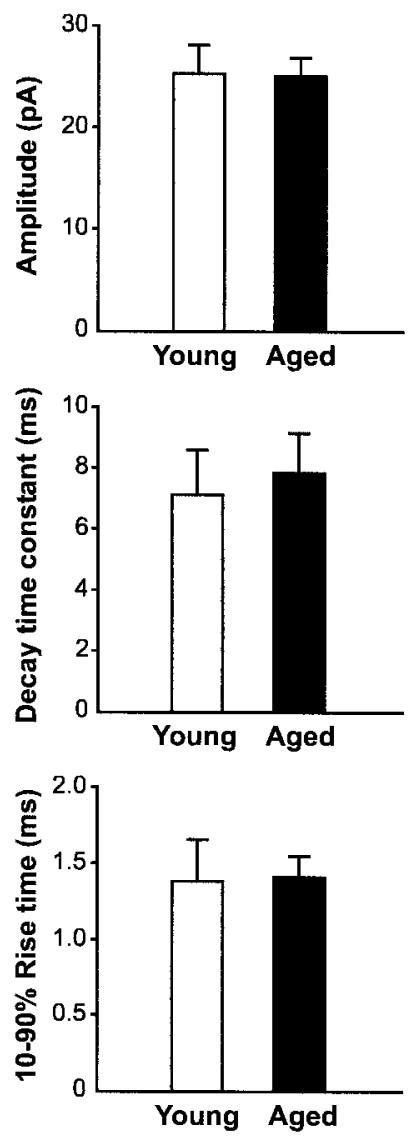
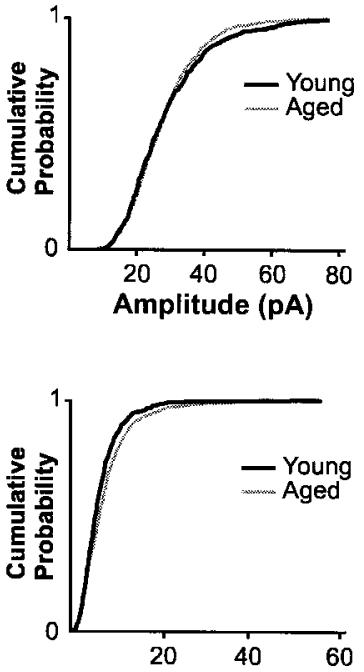

Decay time constant (ms)

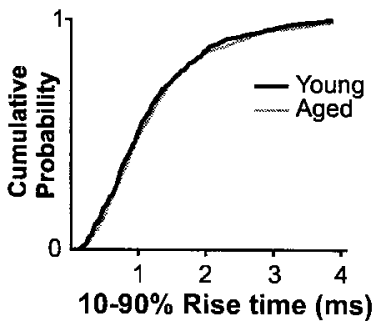

Figure 10. Amplitude and kinetics of action potential-independent mPSCs are not altered in aged rats. Comparison of the amplitude, 10-90\% rise time, and decay time constant of mEPSCs $(A)$ and mIPSCs $(B)$ between young and aged pyramidal neurons. The cumulative probability plots on the right of each histogram further illustrate the lack of change in the distribution of these parameters for both mEPSCs and mIPSCs with aging. These plots were constructed by adding equal sets of 100 consecutive mPSCs taken from each neuron (1500 events in young and 1700 events in aged animals).

determining the excitability of a neuron, the maintenance of this ratio may explain the lack of any drastic change in the spontaneous firing rates of layer $\mathrm{V}$ neurons in aged rats (Lamour et al., 1985; Stern et al., 1985).

Although we observed similar levels of sPSCs frequency in young and aged rats, the amplitude of sEPSCs was significantly lower in the aged brain. This decrease cannot be explained by a smaller quantal size of EPSCs in aged rats because no difference in the amplitude of mEPSCs was found. SPSCs are likely the result of summation of unitary components that occur synchronously from adjacent terminals originating from the same presynaptic neuron (Williams et al., 1998). Thus, desynchronization of neurotransmitter release might explain the reduced amplitude of sEPSCs in aged brain. Such desynchronization may be the result of greater separation of terminals in aged brain given the loss of presynaptic terminals we reported. On the other hand, a possible higher frequency of action potentials in aged brain may also increase the level of branch point failures, thus resulting in a lower degree of summation (Migliore, 1996).

\section{Functional implications}

Although the reduction in synaptic substrate has been regarded as the primary cause of cognitive decline in aging (Chen et al., 1995; Wong et al., 1998) or Alzheimer's disease (DeKosky and Scheff, 1990; Terry et al., 1991), active elimination of synapses may also play an important role in the normal developmental process. For example, in primates, synaptic density in the cerebral cortex has been shown to reach its maximum at 1 month postnatal, to begin its decline at 3 months, and to continue to decline gradually throughout the remainder of its lifespan (Markus et al., 1987). Yet, loss of synapses is not necessarily equivalent to functional deficits. In the present study for example, we observed an increase in action potential-dependent spontaneous synaptic events after a significant loss of synapses in aged rats, thus maintaining a comparable level of inputs to layer $\mathrm{V}$ pyramidal neurons.

Several studies have shown no significant changes in single-unit neuronal activity in either the cerebral cortex (Lamour et al., 1985) or hippocampus (Barnes, 1994). In the present study, we observed a similar ratio of sEPSCs versus sIPSCs in young and aged rats. The balance between these two types of activity may therefore preserve a normal level of excitability in layer $\mathrm{V}$ pyramidal neurons in the parietal cortex. Indeed, failure to maintain this balance has been suggested to be the prime factor in the induction of seizures (Mody et al., 1992).

The maintenance of balanced spontaneous synaptic activity in the aged neocortex may have important functional significance. Brewer et al. (1998) have shown that firing in the prefrontal cortex, measured by functional magnetic resonance imaging, actually correlated with the remembrance of visual experience. The lack of a major decrease in cortical neuronal activity in aging may explain the moderate cognitive impairment observed in normal aging when compared with pathological conditions such as Alzheimer's disease (Dalla and Boller, 1998), in which a more drastic losses of neurons and synaptic structures is observed (Coleman and Flood, 1987; Masliah et al., 1989; DeKosky and Scheff, 1990; Terry et al., 1991; 
West et al., 1994). This more drastic loss may therefore result in compromised compensatory ability to maintain normal or balanced neuronal activity.

\section{REFERENCES}

Adams I (1987) Comparison of synaptic changes in the precentral and postcentral cerebral cortex of aging humans: a quantitative ultrastructural study. Neurobiol Aging 8:203-212.

Bao J, Li JJ, Perl ER, Lehre KP, Danbolt NC (1998) Differences in Ca ${ }^{2+}$ channels governing generation of miniature and evoked excitatory synaptic currents in spinal laminae I and II. J Neurosci 18:8740-8750.

Barnes CA (1994) Normal aging: regionally specific changes in hippocampal synaptic transmission. Trends Neurosci 17:13-18.

Blue ME, Parnavelas JG (1983) The formation and maturation of synapses in the visual cortex of the rat. I. Qualitative analysis. J Neurocytol 12:599-616.

Bourgeois JP, Rakic P (1993) Changes of synaptic density in the primary visual cortex of the macaque monkey from fetal to adult stage. $\mathrm{J}$ Neurosci 13:2801-2820.

Brewer JB, Z hao Z, Desmond JE, Glover GH, Gabrieli JD (1998) Making memories: brain activity that predicts how well visual experience will be remembered. Science 281:1185-1187.

Buell SJ, Coleman PD (1979) Dendritic growth in the aged human brain and failure of growth in senile dementia. Science 206:854-856.

Chen KS, Masliah E, Mallory M, Gage FH (1995) Synaptic loss in cognitively impaired aged rats is ameliorated by chronic human nerve growth factor infusion. Neuroscience 68:19-27.

Chéry N, De Koninck Y (1999) Junctional versus extrajunctional glycine and GABA(A) receptor-mediated IPSCs in identified lamina I neurons of the adult rat spinal cord. J Neurosci 19:7342-7355.

Coleman PD, Flood DG (1987) Neuron numbers and dendritic extent in normal aging and Alzheimer's disease. Neurobiol Aging 8:521-545.

Côté SL, Ribeiro-da-Silva A, Cuello AC (1993) Current protocols for light microscopy immunocytochemistry. In: Immunohistochemistry II (Cuello AC, ed), pp 147-168. West Sussex: Wiley.

Dalla BG, Boller F (1998) Memory and language in neurodegenerative diseases. Curr Opin Neurol 11:429-433.

de Brabander JM, Kramers RJ, Uylings HB (1998) Layer-specific dendritic regression of pyramidal cells with ageing in the human prefrontal cortex. Eur J Neurosci 10:1261-1269.

De Felipe J, Farinas I (1992) The pyramidal neuron of the cerebral cortex: morphological and chemical characteristics of the synaptic inputs. Prog Neurobiol 39:563-607.

De Koninck Y, Mody I (1994) Noise analysis of miniature IPSCs in adult rat brain slices: properties and modulation of synaptic GABAA receptor channels. J Neurophysiol 71:1318-1335.

De Koninck Y, Ribeiro-da-Silva A, Henry JL, Cuello AC (1992) Spinal neurons exhibiting a specific nociceptive response receive abundant substance P-containing synaptic contacts. Proc Natl Acad Sci USA 89:5073-5077.

DeKosky ST, Scheff SW (1990) Synapse loss in frontal cortex biopsies in Alzheimer's disease: correlation with cognitive severity. Ann Neurol 27:457-464.

Feldman ML (1984) Morphology of the neocortical pyramidal neuron. In: Cerebral cortex (Peters A, Jones EG, eds), pp 123-200. New York: Plenum.

Feldman ML, Dowd C (1975) Loss of dendritic spines in aging cerebral cortex. Anat Embryol (Berl) 148:279-301.

Fox NC, Freeborough PA, Rossor MN (1996) Visualisation and quantification of rates of atrophy in Alzheimer's disease. Lancet 348:94-97.

Fox NC, Warrington EK, Rossor MN (1999) Serial magnetic resonance imaging of cerebral atrophy in preclinical Alzheimer's disease. Lancet 353:2125.

Govoni S, Memo M, Saiani L, Spano PF, Trabucchi M (1980) Impairment of brain neurotransmitter receptors in aged rats. Mech Ageing Dev 12:39-46.

Gray EG (1969) Electron microscopy of excitatory and inhibitory synapses: a brief review. Prog Brain Res 31:141-155.

Gur RC, Gur RE, Obrist WD, Skolnick BE, Reivich M (1987) Age and regional cerebral blood flow at rest and during cognitive activity. Arch Gen Psychiatry 44:617-621.

Hazzard DG, Bronson RT, McClearn GE, Strong R (1992) Selection of an appropriate animal model to study aging processes with special emphasis on the use of rat strains. J Gerontol 47:B63-B64.

Huttenlocher PR (1979) Synaptic density in human frontal cortex-developmental changes and effects of aging. Brain Res 163:195-205.

Jack Jr CR, Petersen RC, Xu Y, O'Brien PC, Smith GE, Ivnik RJ, Tangalos EG, Kokmen E (1998) Rate of medial temporal lobe atrophy in typical aging and Alzheimer's disease. Neurology 51:993-999.

Jackson MB (1992) Cable analysis with the whole-cell patch clamp. Theory and experiment. Biophys J 61:756-766.

Jacobs B, Driscoll L, Schall M (1997) Life-span dendritic and spine changes in areas 10 and 18 of human cortex: a quantitative Golgi study. J Comp Neurol 386:661-680.
Koenderink MJ, Uylings HB, Mrzljak L (1994) Postnatal maturation of the layer III pyramidal neurons in the human prefrontal cortex: a quantitative Golgi analysis. Brain Res 653:173-182.

Kossut M, Stewart MG, Siucinska E, Bourne RC, Gabbott PL (1991) Loss of gamma-aminobutyric acid (GABA) immunoreactivity from mouse first somatosensory (SI) cortex following neonatal, but not adult, denervation. Brain Res 538:165-170.

Lamour Y, Dutar P, Jobert A (1985) Cerebral neocortical neurons in the aged rat: spontaneous activity, properties of pyramidal tract neurons and effect of acetylcholine and cholinergic drugs. Neuroscience 16:835-844.

Landry P, Wilson CJ, Kitai ST (1984) Morphological and electrophysiological characteristics of pyramidal tract neurons in the rat. Exp Brain Res 57:177-190.

Larkman AU (1991) Dendritic morphology of pyramidal neurones of the visual cortex of the rat: I. Branching patterns. J Comp Neurol 306:307-319.

Leenders KL, Perani D, Lammertsma AA, Heather JD, Buckingham P, Healy MJ, Gibbs JM, Wise RJ, Hatazawa J, Herold S (1990) Cerebral blood flow, blood volume and oxygen utilization. Normal values and effect of age. Brain 113:27-47.

Leuba G (1983) Aging of dendrites in the cerebral cortex of the mouse. Neuropathol Appl Neurobiol 9:467-475.

Lolova I, Lolov V, Itsev D, Petkov VD (1990) Changes in the synapses in the parietal cortex of senescent rats. Acta Physiol Pharmacol Bulg 16:42-49.

Luhmann HJ, Prince DA (1991) Postnatal maturation of the GABAergic system in rat neocortex. J Neurophysiol 65:247-263.

Ma W, Ribeiro-da-Silva A, De Koninck Y, Radhakrishnan V, Henry JL, Cuello AC (1996) Quantitative analysis of substance P-immunoreactive boutons on physiologically characterized dorsal horn neurons in the cat lumbar spinal cord. J Comp Neurol 376:45-64.

Markus EJ, Petit TL (1987) Neocortical synaptogenesis, aging, and behavior: lifespan development in the motor-sensory system of the rat. Exp Neurol 96:262-278.

Markus EJ, Petit TL, LeBoutillier JC (1987) Synaptic structural changes during development and aging. Dev Brain Res 432:239-248.

Masliah E, Terry RD, DeTeresa RM, Hansen LA (1989) Immunohistochemical quantification of the synapse-related protein synaptophysin in Alzheimer disease. Neurosci Lett 103:234-239.

McKinney RA, Capogna M, Durr R, Gahwiler BH, Thompson SM (1999) Miniature synaptic events maintain dendritic spines via AMPA receptor activation. Nat Neurosci 2:44-49.

Melamed E, Lavy S, Bentin S, Cooper G, Rinot Y (1980) Reduction in regional cerebral blood flow during normal aging in man. Stroke 11:31-35.

Mhatre MC, Ticku MK (1992) Aging related alterations in $\mathrm{GABA}_{\mathrm{A}}$ receptor subunit mRNA levels in Fischer rats. Mol Brain Res 14:71-78.

Mhatre MC, Fernandes G, Ticku MK (1991) Aging reduces the mRNA of alpha 1 GABAA receptor subunit in rat cerebral cortex. Eur J Pharmacol 208:171-174.

Migliore M (1996) Modeling the attenuation and failure of action potentials in the dendrites of hippocampal neurons. Biophys J 71:2394-2403.

Mody I, Otis TS, Staley KJ, Kohr G (1992) The balance between excitation and inhibition in dentate granule cells and its role in epilepsy. Epilepsy Res [Suppl] 9:331-339.

Nakamura S, Akiguchi I, Kameyama M, Mizuno N (1985) Age-related changes of pyramidal cell basal dendrites in layers III and V of human motor cortex: a quantitative Golgi study. Acta Neuropathol 65:281-284.

Paxinos G, Watson C (1986) The rat brain in stereotaxic coordinates. Sydney: Academic.

Post-Munson DJ, Lum-Ragan JT, Mahle CD, Gribkoff VK (1994) Reduced bicuculline response and GABAA agonist binding in aged rat hippocampus. Neurobiol Aging 15:629-633.

Rall W (1969) Time constants and electrotonic length of membrane cylinders and neurons. Biophys J 9:1483-1508.

Rall W, Segev I (1985) Space-Clamp problems when voltage clamping branched neurons with intracellular microelectrodes. In: Voltage and patch clamping with microelectrodes (Smith TGJ, Lecar H, Redman SJ, Gage PW, eds), pp 191-215. Baltimore: Waverly.

Richerson GB, Messer C (1995) Effect of composition of experimental solutions on neuronal survival during rat brain slicing. Exp Neurol 131:133-143.

Roy D, Singh R (1988) Age-related change in the multiple unit activity of the rat brain parietal cortex and the effect of centrophenoxine. Exp Gerontol 23:161-174.

Salin PA, Prince DA (1996) Spontaneous GABAA receptor-mediated inhibitory currents in adult rat somatosensory cortex. J Neurophysiol 75:1573-1588.

Shaw TG, Mortel KF, Meyer JS, Rogers RL, Hardenberg J, Cutaia MM (1984) Cerebral blood flow changes in benign aging and cerebrovascular disease. Neurology 34:855-862.

Soltesz I, Smetters DK, Mody I (1995) Tonic inhibition originates from synapses close to the soma. Neuron 14:1273-1283.

Spangler EL, Waggie KS, Hengemihle J, Roberts D, Hess B, Ingram DK (1994) Behavioral assessment of aging in male Fischer 344 and Brown Norway rat strains and their F1 hybrid. Neurobiol Aging 15:319-328. 
Spruston N, Johnston D (1992) Perforated patch-clamp analysis of the passive membrane properties of three classes of hippocampal neurons. J Neurophysiol 67:508-529.

Spruston N, Jaffe DB, Johnston D (1994) Dendritic attenuation of synaptic potentials and currents: the role of passive membrane properties. Trends Neurosci 17:161-166.

Staley KJ, Mody I (1992) Shunting of excitatory input to dentate gyrus granule cells by a depolarizing GABAA receptor-mediated postsynaptic conductance. J Neurophysiol 68:197-212.

Stern WC, Pugh WW, Morgane PJ (1985) Single unit activity in frontal cortex and caudate nucleus of young and old rats. Neurobiol Aging 6:245-248.

Sutor B, Luhmann HJ (1995) Development of excitatory and inhibitory postsynaptic potentials in the rat neocortex. Perspect Dev Neurobiol 2:409-419.

Terry RD, Masliah E, Salmon DP, Butters N, Deteresa R, Hill R, Hansen LA, Katzman R (1991) Physical basis of cognitive alterations in Alzheimer's disease: synapse loss is the major correlate of cognitive impairment. Ann Neurol 30:572-580.
Uchizono K (1965) Characteristics of excitatory and inhibitory synapses in the central nervous system of the cat. Nature 207:642-643.

Wenk GL, Walker LC, Price DL, Cork LC (1991) Loss of NMDA, but not GABA-A, binding in the brains of aged rats and monkeys. Neurobiol Aging 12:93-98.

West MJ, Coleman PD, Flood DG, Troncoso JC (1994) Differences in the pattern of hippocampal neuronal loss in normal ageing and Alzheimer's disease. Lancet 344:769-772.

White EL (1989) Cortical circuits: synaptic organization of the cerebral cortex structure, function, and theory. Boston: Birkhauser.

Williams SR, Buhl EH, Mody I (1998) The dynamics of synchronized neurotransmitter release determined from compound spontaneous IPSCs in rat dentate granule neurones in vitro. J Physiol (Lond) 510:477-497.

Wong TP, Campbell PM, Ribeiro-da-Silva A, Cuello AC (1998) Synaptic numbers across cortical laminae and cognitive performance of the rat during ageing. Neuroscience 84:403-412.

Zecevic N, Bourgeois JP, Rakic P (1989) Changes in synaptic density in motor cortex of rhesus monkey during fetal and postnatal life. Brain Res Dev Brain Res 50:11-32. 